\title{
Exploiting the SISALv2 database for evaluating climate processes
}

Yassine Ait Brahim¹, J. Hu², J. Baker' ${ }^{1}$ C. Perez-Mejias' ${ }^{1}$, H. Zhang ${ }^{1}$ and L. Comas-Bru ${ }^{3}$

\author{
4th SISAL workshop, Xi'an, China, 14-18 October 2019
}

The SISAL working group (Speleothem Isotope Synthesis and Analysis;

pastglobalchanges.org/sisal) dedicated its initial phase to creating and maintaining a database of worldwide speleothem $\delta^{18} \mathrm{O}$ and $\delta^{13} \mathrm{C}$ records. The first version of the database (Atsawawaranunt et al. 2018a) contained 381 speleothem records and was published in 2018 (Atsawawaranunt et al. 2018b). An expansion of the database (SISALv1b; Atsawawaranunt et al. 2019) increased that number to 456 records from 211 sites (Comas-Bru et al. 2019). Thanks to the efforts of SISAL's committed members, the second version of the database (SISALv2), containing 691 records, will be made available in 2020 .

Twenty-seven SISAL members (including 22 early-career researchers and 13 female researchers) from 12 countries gathered at Jiaotong University in Xi'an, China, for the fourth SISAL workshop (pastglobalchanges. org/calendar/2019/127-pages/1942). The main goals of this meeting were to finalize ongoing tasks related to the construction of SISALv2, attempt to resolve research questions by improving data-model comparisons through SISALv2, host a training session on database utilization and analysis, and finally to discuss and organize prospective projects under SISAL.

The workshop kicked off with a visit to the archaeological site of the Terracotta Warriors and Horses and the Lantian loess field, $35 \mathrm{~km}$ east of $X_{i}{ }^{\prime} a n$. During the evening, invited speakers gave presentations about multiscale climate variability in Iberia (Dr. Ana Moreno), multiscale climate variability in South America (Prof. Francisco W. Cruz) and advancements on the application of fluid inclusions in speleothems (Dr. Hubert Vonhof).
On the morning of day two, the lead coordinator of SISAL (Dr. Laia Comas-Bru) provided an overview on the progress of SISAL and its ongoing activities. Afterwards, selected participants presented their work on regional climate patterns inferred from speleothems, as published in our Quaternary special issue on "Speleothem Records and Climate" (Harrison and Comas-Bru 2019). During the afternoon session, presentations focused on isotope-enabled climate models and data-model comparisons. The day closed with local researchers presenting their own speleothem-based research.

On days three and four, the workshop was structured as a mixture of training and analysis sessions. The analysis stream took advantage of the balanced representation of speleothem researchers and climate modelers present at the workshop to design new hypotheses, which could be addressed using the new version of the SISAL database and currently available isotope-enabled climate models. Participants divided into three breakout groups focused on individual time periods and/or climate events to identify analyses that could be of interest to the Palaeoclimate Modelling Intercomparison Project (PMIP) community. Additionally, some attendees worked on a handbook for reporting speleothem isotope records, drawing from experience gathered by the SISAL initiative. The training stream was open to anyone interested, with the aim to teach researchers how to use the SISAL database. Participants had the opportunity to learn how to fill in SISAL workbooks and run quality-control scripts to check their consistency and readiness to be uploaded to the database. Participants were given a basic introduction on the structure of the SISAL database and the most common MySOL commands needed to extract data from the database. In addition, tutors illustrated how to read, plot, and carry out analyses using the SISAL database. The examples included plotting multiple speleothem timeseries with age error bars, plotting a map of prefiltered sites, applying low-pass filtering, and conducting correlation and spectral analysis. The training stream is among the new initiatives taken by SISAL, and the group intends to run similar sessions at other conferences such as KR9 (uibk.ac.at/congress/kr9/ scientific-programme/workshops.html).

\section{ACKNOWLEDGEMENTS}

We thank the hosts, Prof. Hai Cheng, and all the students of XJTU Isotope Laboratory who ensured that everything ran smoothly during the workshop. Organizers would also like to thank PAGES, National Natural Science Foundation of China (project number: NSFC 41888101 and 41942012), and Xi'an Jiaotong University for their financial support.

\section{AFFILIATIONS}

'Xi'an Jiatong University, China

${ }^{2}$ Rice University, Houston, TX, USA

3University of Reading, UK

\section{CONTACT}

Yassine Ait Brahim: aitbrahim@xjtu.edu.cn

\section{REFERENCES}

Atsawawaranunt K et al. (2018a) SISAL database Version 1.0. University of Reading. Dataset

Atsawawaranunt K et al. (2018b) Earth Syst Sci Data 10: 1687-1713

Atsawawaranunt K et al. (2019) SISAL database Version 1b. University of Reading. Dataset

Comas-Bru L et al. (2019) Clim Past 15: 1557-1579

Harrison SP, Comas-Bru L (Eds) (2019) Quaternary (special issue) Speleothem Records and Climate

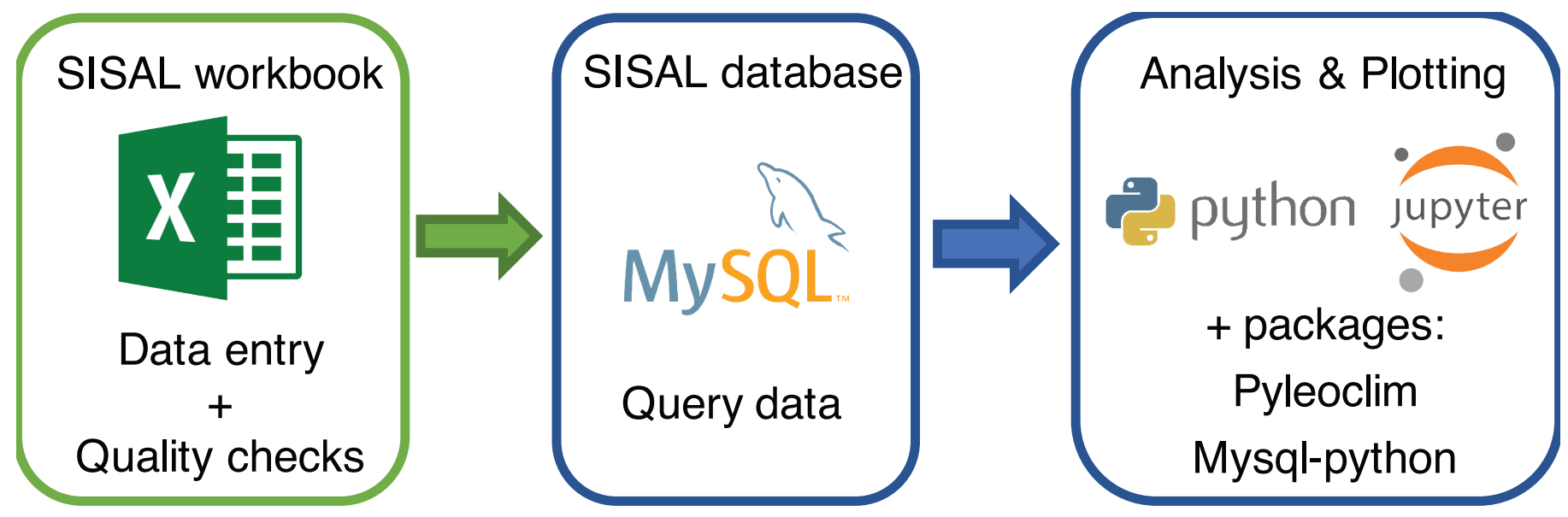

Figure 1: The workflow of the training sessions. Three main tasks are data entry and quality checks of SISAL workbooks; querying data from SISAL database; and plotting/ conducting analyses using the database. 